\title{
Ảnh hưởng của nhiệt độ sấy đến hàm lượng hợp chất polyphenol, sắc tố carotenoids, chlorophyll và hoạt tính chống oxy hóa của cây rau càng cua (Peperomia pellucida $L$.) thu ở tỉnh Tiền Giang
}

\section{The effects of drying temperature on the content of polyphenol compounds, carotenoids, chlorophyll pigmented and antioxidant activity of the "rau cang cua" (Peperomia pellucida L.) collected in Tien Giang province}

Trương Quốc Tất ${ }^{*}$, Phùng Thị Thúy Liễu ${ }^{1}$, Nguyễn Thị Phương Trang ${ }^{1}$, Nguyễn Duy Khánh ${ }^{2}$

${ }^{1}$ Trường Đại học Tiền Giang, Việt Nam

${ }^{2}$ Học viên cao học, Trường Đại học Cần Thơ, Việt Nam

*Tác giả liên hệ, Email: truongquoctat@tgu.edu.vn

THÔNG TIN

DOI: $10.46223 /$ HCMCOUJS. tech.vi.16.1.1891.2021

Ngày nhận: 24/05/2021

Ngày nhận lại: 05/07/2021

Duyệt đăng: 08/07/2021

Tù̀ khóa:

chống oxy hóa; Peperomia pellucida L.; polyphenol; rau càng cua; sấy

Keywords:

antioxidant activity; drying; Peperomia pellucida L.; polyphenol; rau cang cua

\section{TÓM TẮT}

Mục tiêu của nghiên cứu này là đánh giá sự ảnh hưởng của nhiệt độ sấy đến hàm lượng của các hợp chất có giá trị sinh học trong cây rau càng cua (Peperomia pellucida L.) và hoạt tính chống oxy hóa của dịch trích của nó. Cây rau càng cua được sấy ở các mức nhiệt độ $50,60,70$ và $80^{\circ} \mathrm{C}$ đến độ ẩm đạt $\leq 10 \%$, sau đó rau càng cua khô được nghiền và rây để thu bột mịn. Bột rau càng cua được trích ly bằng ethanol $70 \%$, thu dịch và tiến hành phân tích các chỉ tiêu polyphenol tổng số (TPP), sắc tố carotenoids, chlorophyll và phần trăm gốc tự do $\mathrm{DPPH}$ bị khử. Kết quả nghiên cứu khi sấy rau càng cua ở nhiệt độ $50-80^{\circ} \mathrm{C}$, hàm lượng TPP dao động trong khoảng 6.65-12.88 (mgGAE/g DM), carotenoids dao động trong khoảng 96.88-132.78 ( $\mu \mathrm{g} / \mathrm{g} \mathrm{DM})$, chlorophyll $\mathrm{a}$ và $\mathrm{b}$ lần lượt dao động trong khoảng 800.5-1,205.60 ( $\mu \mathrm{g} / \mathrm{g} \mathrm{DM})$ và $560.94-665.40(\mu \mathrm{g} / \mathrm{g} \mathrm{DM})$ và phần trăm khử gốc tự do DPPH dao động trong khoảng 53.73-69.54\%. Các mẫu rau càng cua được sấy ở nhiệt độ $70^{\circ} \mathrm{C}$ giữ lại hàm lượng TPP, khả năng chống oxy hóa tốt hơn và đồng thời giữ lại màu sắc khá tốt so với 03 mẫu còn lại.

\section{ABSTRACT}

The objective of this study is to determine the effect of the drying temperature on the content of the bio-compounds in "rau cang cua" (Peperomia pellucida L.) and antoxidant of these extract. They were dried to the moisture content of $\leq 10 \%$ at the temperatures of $50,60,70$, and $80^{\circ} \mathrm{C}$, and then they were finely ground to powder. "Rau cang cua" powder was extracted with ethanol $70 \%$, received extracts and analyzed The Total Polyphenol (TPP), carotenoids, chlorophyll pigmented and the 
percentage of scavenging free radical DPPH. When "rau cang cua" were dried at the temperature of $50-80^{\circ} \mathrm{C}$, TPP content ranged 6.65-12.88 (mgGAE/g DM), carotenoids ranged 96.88$132.78(\mu \mathrm{g} / \mathrm{g} \mathrm{DM})$, chlorophyll a and b ranged 800.59-1,205.60 and 560.94-665.40 ( $\mu \mathrm{g} / \mathrm{g} \mathrm{DM})$ respectively and the percentage of scavenging free radical DPPH ranged 53.73-69.54\%. The "rau cang cua" samples were dried at the temperature of $70^{\circ} \mathrm{C}$ had TPP content, antioxidant higher and it also retain the color pretty good compared with 03 remain samples.

\section{Giới thiệu}

Rau càng cua (Peperomia pellucida L.) là loại rau quen thuộc đối với người Việt Nam. Rau càng cua không chỉ được dùng như 01 loại rau xanh mà còn là một vị thuốc tốt cho sức khỏe trong các bài thuốc dân gian. Theo đông $\mathrm{y}$, rau càng cua có tính bình, mọng nước, mùi hơi hăng, thanh mát và có vị chua nhẹ, có tác dụng thanh nhiệt, giải độc, hoạt huyết, thường dùng để chữa các bệnh nhiễm trùng đường hô hấp, viêm họng, tiêu hóa kém, đau nhức xương khớp. Trong một số nghiên cứu gần đây, các nhà khoa học đã phân tích thành phần hóa học của cây rau càng cua. Kết quả cho thấy rau càng cua giàu vitamin $C$, khoáng Kali và Canxi, tinh dầu và chứa đa dạng các hoạt chất sinh học. Trong đó nổi bật là nhóm hợp chất polyphenol. Polyphenol hay phenolic là nhóm những hợp chất thơm có nhóm hydroxyl gắn trực tiếp với nhân benzene (Le, 2003). Chúng không chỉ có chức năng sinh lý đối với thực vật mà còn có nhiều tác dụng tích cực đối với sức khỏe con người do có tác dụng chống oxi hóa mạnh, kháng viêm, kháng khuẩn tự nhiên.

Nhiều nghiên cứu đã cho thấy các chất chống oxy hóa tự nhiên có khả năng ngăn ngừa và hỗ trợ điều trị các bệnh tật nguy hiểm ở người như: ung thư, tim mạch, thoái hóa và rối loạn thần kinh như pakinson hay alzheimer; các bệnh liên quan đến đường huyết cao; bệnh xương khớp (Uddin, Akond, Mubassara, \& Yesmin, 2008). Tuy nhiên, nhiều nghiên cứu đã cho thấy hàm lượng polyphenol và khả năng chống oxy hóa của nguyên liệu dễ bị biến đổi bởi điều kiện của môi trường đặc biệt là nhiệt độ. Do đó, việc nghiên cứu đánh giá sự ảnh hưởng của nhiệt độ sấy đến hàm lượng polyphenol tồng số và khả năng chống oxy hóa của rau càng cua trong quá trình sấy là việc làm đầu tiên để xác định nhiệt độ sấy thích hợp cho rau càng cua để làm nguyên liệu cho việc nghiên cứu trích ly hợp chất polyphenol có khả năng chống oxy hóa.

\section{Vật liệu và phương pháp nghiên cứu}

\subsection{Vật liệu nghiên cú́u}

\subsubsection{Mẫu}

Các mẫu rau càng cua được thu hái trong các vườn trồng thanh long ở huyện Chợ Gạo, tỉnh Tiền Giang vào mùa khô (tháng 04/2021). Sau đó, các mẫu rau càng cua được loại bỏ rễ, làm sạch, cân $(300 \mathrm{~g} / \mathrm{mẻ}$ sấy) sẵn sàng cho quá trình sấy (Hình 1$)$.

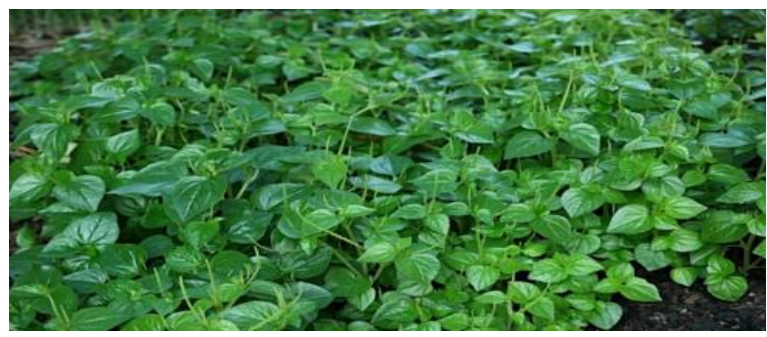

Hình 1. Mẫu rau càng cua 


\subsubsection{Hóa chất}

Chất chuẩn gallic acid, thuốc thử Folin-Ciocalteu (Merck, Đức); 2,2 diphenyl 1-2picrylhydrazyl (DPPH) (TCI, Nhật Bản); Ethanol tuyệt đối (Cemaco, Việt Nam), $\mathrm{Na}_{2} \mathrm{CO}_{3}$ (Trung Quốc).

\subsection{Phwơng pháp nghiên cúu}

\subsubsection{Bố trí thí nghiệm}

Thí nghiệm đánh giá sự ảnh hưởng của nhiệt độ sấy đến hàm lượng hợp chất TPP và 02 loại sắc tố của cây rau càng cua được bố trí hoàn toàn ngẫu nhiên gồm 04 nghiệm thức (các mức nhiệt độ sấy $50,60,70$ và $80^{\circ} \mathrm{C}$ ), mỗi nghiệm thức được lặp lại 03 lần. Các mẫu rau càng cua được làm khô bằng phương pháp sấy đối lưu nhiệt với tủ sấy Yamato DK412C (Japan). Các mẫu rau càng cua khô (độ ẩm $\leq 10 \%$ ) được nghiền mịn, rây và thu bột, trích ly và tiến hành phân tích hàm lượng hợp chất TPP, sắc tố chlorophyll và carotenoids và khả năng khử gốc tự do DPPH.

\subsubsection{Chuẩn bị dịch phân tích}

Cân chính xác $0.5 \mathrm{~g}$ mẫu khô cho vào ống nghiệm có nắp dung tích $50 \mathrm{~mL}$. Sau đó, cho $25 \mathrm{~mL}$ ethanol $70 \%$ vào mỗi ống, để yên ở nhiệt độ phòng trong 30 phút, tiếp theo cho vào bể ổn nhiệt và giữ trong thời gian 30 phút ở nhiệt độ $55^{\circ} \mathrm{C}$. Kết thúc 30 phút, lấy các ống ra khỏi bể và ngâm vào nước đá để làm lạnh nhanh đến nhiệt độ phòng nhằm ngưng quá trình trích $1 \mathrm{y}$. Sau đó, đem các ống đi ly tâm ở tốc độ 5,500rpm trong 15 phút để thu dịch trích. Dịch trích được chứa trong bình định mức dung tích $50 \mathrm{~mL}$, thêm dung môi tương ứng vào để định lượng về cùng một thể tích $50 \mathrm{~mL}$ để dễ tính toán về sau, đậy nắp kín. Dịch trích có thể được bảo quản ở $-20^{\circ} \mathrm{C}$ nhằm tránh sự biến đổi của các hoạt chất sinh học nếu chưa phân tích.

\subsubsection{Xác định hàm lượng polyphenol tổng số (TPP)}

Hàm lượng hợp chất TPP được xác định theo phương pháp Folin-Ciocalteau dựa trên mô tả của Yadav và Agarwala (2011). Dung dịch gallic acid có nồng độ $0,20,40,60,80$ và $100 \mu \mathrm{g} / \mathrm{mL}$ lần lượt được hút $1 \mathrm{~mL}$ vào các ống nghiệm, tiếp tục thêm $2.5 \mathrm{~mL}$ dung dịch FolinCiocalteu $10 \%$, lắc đều hỗn hợp trong 5 phút. Sau đó, thêm tiếp $2 \mathrm{~mL}$ dung dịch $\mathrm{Na}_{2} \mathrm{CO}_{3} 2 \%$. Hỗn hợp được lắc đều, giữ trong bóng tối 60 phút ở nhiệt độ phòng và sau đó xác định độ hấp thụ $\mathrm{OD}$ ở bước sóng $\lambda=765 \mathrm{~nm}$. Các giá trị $\mathrm{OD}$ được ghi nhận và vẽ đường thẳng hiệu chuẩn để sử dụng xác định hàm lượng hợp chất TPP trong các mẫu dịch trích. Các mẫu dịch trích được tiến hành tương tự với mẫu polyphenol chuẩn. Hàm lượng hợp chất TPP được tính theo công thức:

$$
\mathrm{P}=\frac{\mathrm{a} \times \mathrm{V} \times \mathrm{K}}{1000 \times \mathrm{m} \times(1-\mathrm{w})}
$$

Trong đó: $\mathrm{P}$ là hàm lượng TPP (mgGAE/g DM) với DM: Dry Material; a là giá trị $\mathrm{x}$ từ đường chuẩn với gallic acid $(\mu \mathrm{gGAE} / \mathrm{mL}) ; \mathrm{V}$ là thể tích dung dịch trích $(\mathrm{mL}) ; \mathrm{m}$ là khối lượng bột rau càng cua $(\mathrm{g})$; w là độ ẩm của bột rau càng cua; $\mathrm{K}$ là độ pha loãng.

\subsubsection{Xác định hoạt tính chống oxy hóa}

Hoạt tính chống oxy hóa của mẫu dịch trích rau càng cua được xác định theo phương pháp khử gốc tự do DPPH dựa trên mô tả của Aluko, Alli, và Omoyeni (2014). Hút 1mL dung dịch 2, 2 diphenyl 1-2-picrylhydrazyl (DPPH) $0.135 \mathrm{mM}$ pha trong ethanol tuyệt đối $(99.5 \%)$ và $1 \mathrm{~mL}$ của dịch trích. Giữ hỗn hợp trong bóng tối 30 phút, sau đó đo độ hấp thu của hỗn hợp ở bước sóng $\lambda=517 \mathrm{~nm}$. Mẫu đối chứng được chuẩn bị bao gồm $1 \mathrm{~mL}$ ethanol $70 \%$ với $1 \mathrm{~mL}$ dung dịch $\mathrm{DPPH} 0.135 \mathrm{mM}$ và cũng được đo độ hấp thu ở bước sóng $517 \mathrm{~nm}$ sau 30 phút giữ trong 
bóng tối. Phần trăm khử gốc tự do DPPH được tính theo công thức:

Phần trăm bị khử $(\%)=[(\mathrm{OD}$ đối chứng $-\mathrm{OD}$ dịch trích $) / \mathrm{OD}$ đối chứng $] \mathrm{x} 100$

Trong đó: $\mathrm{OD}$ đối chứng là độ hấp thu của mẫu đối chứng, $\mathrm{OD}$ dịch trích là độ hấp thu của mẫu dịch trích.

\subsubsection{Xác định hàm lự̛ng 2 sắc tố carotenoids và chlorophyll}

Hàm lượng 2 sắc tố carotenoids và chlorophyll trong dịch trích bột rau càng cua bằng dung môi ethanol 70\% được xác định dựa trên mô tả của (T. D. Nguyen, 2019) có hiệu chỉnh. Dịch trích rau càng cua được đo độ hấp thụ ánh sáng (OD) lần lượt ở các bước sóng $(\lambda)$ là 480 , 645 và $663 \mathrm{~nm}$, với ethanol $70 \%$ làm mẫu trắng. Hàm lượng 02 sắc tố được tính theo công thức:

$$
\begin{aligned}
& \mathrm{A}_{1}=\left[\left(12.7 \times \mathrm{OD}_{663}-2.69 \times \mathrm{OD}_{645}\right) / \mathrm{m} \times(1-\mathrm{w})\right] \times \mathrm{V} \times \mathrm{K} \\
& \mathrm{A}_{2}=\left[\left(22.9 \times \mathrm{OD}_{645}-4.68 \times \mathrm{OD}_{663}\right) / \mathrm{m} \times(1-\mathrm{w})\right] \times \mathrm{V} \times \mathrm{K} \\
& \mathrm{B}=\left[\left(\mathrm{OD}_{480}+0.114 \times \mathrm{OD}_{663}-0.638 \times \mathrm{OD}_{645}\right) / \mathrm{m} \times(1-\mathrm{w})\right] \times \mathrm{V} \times \mathrm{K}
\end{aligned}
$$

Trong đó: $\mathrm{A}_{1}$ : Chlorophyll a $(\mu \mathrm{g} / \mathrm{g} \mathrm{DM}), \mathrm{A}_{2}$ : Chlorophyll b ( $\left.\mu \mathrm{g} / \mathrm{g} \mathrm{DM}\right), \mathrm{B}$ : Carotenoids $(\mu \mathrm{g} / \mathrm{g} \mathrm{DM}) ; \mathrm{OD}_{480}, \mathrm{OD}_{645}, \mathrm{OD}_{663}$ là độ hấp thụ quang của mẫu dịch trích tại bước sóng $(\lambda) 480$, 645 và $663 \mathrm{~nm}$; $\mathrm{V}$ là thể tích dịch trích $(\mathrm{mL}) ; \mathrm{m}$ là khối lượng bột rau càng cua $(\mathrm{g})$; w là độ ẩm của bột rau càng cua; $\mathrm{K}$ là hệ số pha loãng.

\subsubsection{Xủ lý số liệu}

Số liệu của nghiên cứu đã được nhập, tính toán, vẽ biểu đồ bằng phần mềm Excel và xử lý thống kê bằng phần mềm Minitab 16.

\section{Kết quả nghiên cứu và thảo luận}

\subsection{Anh hưởng của nhiệt độ sấy đến sụ biến đổi hàm ẩm theo thời gian}

Trong quá trình sấy, nhiệt độ sấy là yếu tố có ảnh hưởng rất lớn đến sự thoát ẩm từ vật liệu sấy ra môi trường bên ngoài và chất lượng của sản phẩm sấy như: màu sắc, mùi vị và giá trị dinh dưỡng. Các mức nhiệt độ sấy khảo sát trong nghiên cứu sấy cây rau càng cua là $50,60,70$ và $80^{\circ} \mathrm{C}$. Vật liệu sấy (cây rau càng cua) được theo dõi độ ẩm với tần suất 30 phút/lần, quá trình sấy chỉ kết thúc khi độ ẩm của vật liệu đạt $\leq 10 \%$. Kết quả sự ảnh hưởng của nhiệt độ sấy đến sự biến đổi hàm ẩm của cây rau càng cua theo thời gian được thể hiện qua Hình 2.

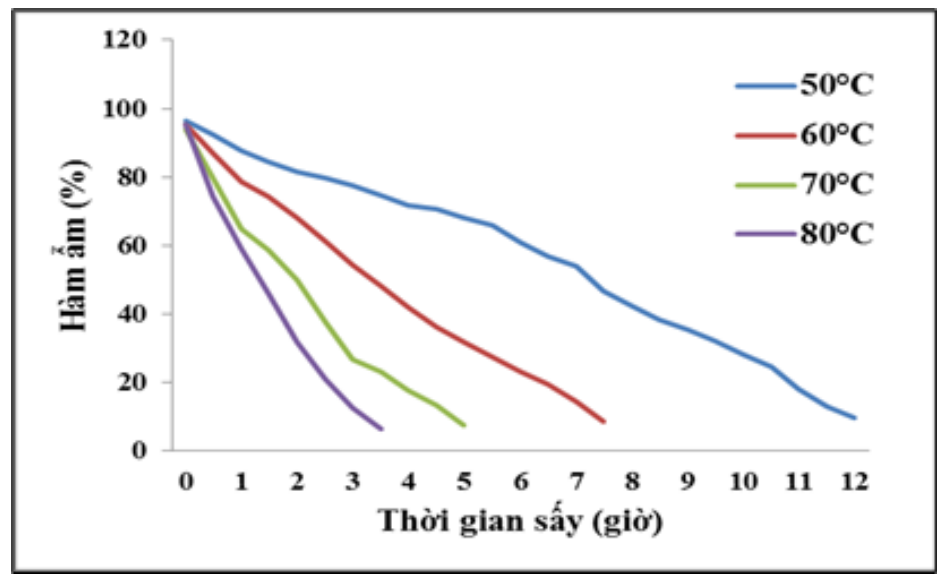

Hình 2. Sự giảm ẩm của vật liệu sấy theo thời gian ở các nhiệt độ

Qua kết quả ở Hình 2 cho thấy nhiệt độ sấy và thời gian sấy có mối tương quan tỷ lệ nghịch. Việc tăng nhiệt độ sấy có tác dụng làm tăng tốc độ sấy, từ đó thời gian sấy nguyên liệu 
được giảm xuống. Thời gian sấy cần thiết để cây rau càng cua đạt độ ẩm $\leq 10 \%$ khi được sấy ở các nhiệt độ $50,60,70$ và $80^{\circ} \mathrm{C}$ lần lượt là $12 ; 7.5 ; 5.0$ và 3.5 giờ với độ ẩm của rau càng cua khô lần lượt là $9.63 ; 8.66 ; 7.58$ và $6.42 \%$. Trong quá trình sấy, ghi nhận tốc độ giảm ẩm mạnh ở giai đoạn đầu do ở giai đoạn này lượng ẩm mất đi là do quá trình bay hơi của nước lớp tự do có liên kết lỏng lẻo trong nguyên liệu và tốc độ thoát ẩm này sẽ giảm dần theo thời gian sấy do hàm ẩm ngày càng ít đi. Trong quá trình sấy, sự chênh lệch áp suất hơi riêng phần ở bề mặt nguyên liệu và môi trường khiến các phân tử nước tại bề mặt nguyên liệu bị bốc hơi, song song đó ẩm bên trong nguyên liệu cũng khuếch tán ra ngoài bề mặt. Nhiệt độ cao có tác dụng tăng khả năng truyền nhiệt của tác nhân sấy vào bên trong vật liệu nguyên liệu tuy nhiên khi nhiệt độ quá cao sẽ làm khô cứng bề mặt vật liệu có tác động xấu đến chất lượng và giá trị cảm quan của sản phẩm.

Bên cạnh đó, các phương trình đường cong sấy dạng $\mathrm{y}=\mathrm{a} \cdot \mathrm{e}^{\mathrm{xp}(-\mathrm{kt})}$ (Bảng 1$)$ được xây dựng đều có hệ số $\mathrm{R}^{2} \geq 0.80$. Theo Guan và Yao (2008) mô hình tương quan tốt cần có hệ số xác định tương quan $\mathrm{R}^{2}$ lớn hơn 0.80 . Vì thế có thể sử dụng các phương trình này để dự đoán sự giảm ẩm trong quá trình sấy cây rau càng cua với các mức nhiệt độ đã khảo sát.

\section{Bảng 1}

Các phương trình đường cong sấy cây rau càng cua theo các mức nhiệt độ sấy khác nhau

\begin{tabular}{ccc}
\hline Nhiệt độ sấy $\left({ }^{\mathbf{0}} \mathbf{C}\right)$ & Phương trình & $\mathbf{R}^{\mathbf{2}}$ \\
\hline 50 & $\mathrm{y}=136.08 \mathrm{e}^{-0.079 \mathrm{x}}$ & 0.8602 \\
\hline 60 & $\mathrm{y}=131.40 \mathrm{e}^{-0.141 \mathrm{x}}$ & 0.9452 \\
\hline 70 & $\mathrm{y}=139.04 \mathrm{e}^{-0.237 \mathrm{x}}$ & 0.9708 \\
\hline 80 & $\mathrm{y}=169.83 \mathrm{e}^{-0.373 \mathrm{x}}$ & 0.9628 \\
\hline
\end{tabular}

*Ghi chú: $\mathrm{y}$ là hàm ẩm (\%) và $\mathrm{x}$ là thời gian sấy (giờ); trong đó $\mathrm{x}$ nằm trong khoảng $0-12$ giờ Nguồn: Tác giả quan sát và tổng hợp

\subsection{Anh hưởng của nhiệt độ sấy đến hàm lựng polyphenol tổng số (TPP) trong rau càng cua}

Hợp chất TPP là một trong những thành phần quan trọng nhất và chiếm tỉ lệ lớn trong thực vật nói chung. Đây là hợp chất có khả năng chống oxy hóa mạnh. Vì vậy, chỉ tiêu này luôn được quan tâm trong nghiên cứu hoạt tính chống oxy hóa của thực vật. Sự biến đổi hàm lượng TPP trong rau càng cua được thu ở huyện Chợ Gạo, tỉnh Tiền Giang ở các mức nhiệt độ sấy được trình bày qua Hình 3 . 


\section{Bảng 2}

Hàm lượng polyphenol tổng số và hoạt tính chống oxy hóa của dịch trích bột càng cua được sấy ở các nhiệt độ khác nhau

\begin{tabular}{ccc}
\hline Nhiệt độ sấy $\left({ }^{\circ} \mathbf{C}\right)$ & $\begin{array}{c}\text { Hàm lượng Polyphenol } \\
\text { tổng số (mgGAE/g DM) }\end{array}$ & $\begin{array}{c}\text { Phần trăm gốc tự do } \\
\text { DPPH bị khử (\%) }\end{array}$ \\
\hline 50 & $8.81 \pm 0.630^{\mathrm{b}}$ & $59.85 \pm 1.542^{\mathrm{b}}$ \\
\hline 60 & $6.65 \pm 1.212^{\mathrm{c}}$ & $53.73 \pm 3.735^{\mathrm{c}}$ \\
\hline 70 & $12.88 \pm 0.535^{\mathrm{a}}$ & $69.54 \pm 1.603^{\mathrm{a}}$ \\
\hline 80 & $10.52 \pm 1.013^{\mathrm{ab}}$ & $64.33 \pm 1.249^{\mathrm{ab}}$ \\
\hline
\end{tabular}

*Ghi chú: (1) các giá trị trong cột được xác định dựa vào phương trình đường chuẩn của gallic acid $(\mathrm{y}=0.0118 \mathrm{x}-$ $\left.0.0095 ; \mathrm{r}^{2}=0.9979\right)$. Trong cùng một cột, các số trung bình theo sau bởi một hoặc những chữ cái giống nhau thì khác biệt không có ý nghĩa thống kê ở mức ý nghĩa 5\% bằng phép thử Tukey.

Nguồn: Tác giả quan sát và tổng hợp

Qua kết quả ở Bảng 2, cho thấy nhiệt độ sấy có tác động đến hàm lượng hợp chất TPP và khả năng chống oxy hóa của dịch trích rau càng cua thông qua phần trăm khử gốc tự do DPPH. Mẫu dịch trích rau càng cua sấy ở $70^{\circ} \mathrm{C}$ có hàm lượng hợp chất TPP cao nhất và khác biệt có ý nghĩa thống kê ở mức ý nghĩa $5 \%$ so với các mẫu còn lại với kết quả phân tích đạt được là 12.88 (mgGAE/g DM), kế đến là dịch trích của mẫu sấy ở $80^{\circ} \mathrm{C}$ với hàm lượng là $10.52(\mathrm{mgGAE} / \mathrm{g}$ $\mathrm{DM})$ và dịch trích của mẫu sấy ở $60^{\circ} \mathrm{C}$ có hàm lượng hợp chất TPP thấp nhất chỉ với 6.65 (mgGAE/g DM). Về hoạt tính chống oxy, dịch trích của mẫu rau càng cua được sấy ở $70^{\circ} \mathrm{C}$ có phần trăm gốc tự do DPPH bị khử cao nhất và khác biệt có ý nghĩa thống kê ở mức ý nghĩa $5 \%$ so với 3 mẫu còn lại với $69.54 \%$ gốc tự do DPPH bị khử. Mẫu dịch trích có phần trăm khử gốc tự do DPPH càng cao thì có hoạt tính chống oxy hóa càng mạnh. Hệ số tương quan Pearson giữa hàm lượng TPP với hoạt tính chống oxy hóa của dịch trích thông qua phần trăm khử gốc tự do $\mathrm{DPPH}$ trong nghiên cứu đã được tìm thấy với $\mathrm{r}=0.982$. Từ đó, có thể nhận định rằng TPP là thành phần chính tạo nên khả năng chống oxy của rau càng cua.

Qua kết quả thí nghiệm này cho thấy nhiệt độ thích hợp để sấy làm rau càng cua là $70^{\circ} \mathrm{C}$. So sánh với một số nghiên cứu khác về vấn đề sấy khô nguyên liệu thực vật cho thấy nhiệt độ sấy tối ưu cho các đối tượng là rất khác nhau như nhiệt độ sấy khô giữ lại hàm lượng hợp chất TPP và khả năng chống oxy hóa cao nhất trong rau sam và tía tô là $50^{\circ} \mathrm{C}$ (Truong \& Nguyen, 2020; Yousefi, Emam-Djomeh, \& Mousavi, 2011); lá húng chanh là $60^{\circ} \mathrm{C}$ (Dwivedy, Rayaguru, \& Sahoo, 2012) hoặc vỏ mãng cầu và đài hoa bụp giấm là $80^{\circ} \mathrm{C}$ (Huynh \& Nguyen, 2018; V. Q. Nguyen, Nguyen, Trinh, \& Nguyen, 2014).

Theo (Schweiggert \& Schieber, 2007) hàm lượng TPP của các nguyên liệu thực vật bị biến đổi do một số tác nhân như: hoạt động của enzyme oxy hóa là polyphenol oxydase và peroxydase, quá trình tự phân hủy do oxy và tác dụng của nhiệt độ cao. Trong đó, enzyme polyphenol oxydase sẽ bị vô hoạt hoàn toàn khi gia nhiệt ở $80^{\circ} \mathrm{C}$ trong 10 phút và ở $90-100^{\circ} \mathrm{C}$ thì enzyme này sẽ bị vô hoạt hoàn toàn.

\subsection{Anh hưởng của nhiệt độ sấy đến hàm lự̆ng của sắc tố chlorophyll và carotenoids trong rau càng cua}

Carotenoids và Chlorophyll là 02 sắc tố hiện diện nhiều trong các loại thực vật và có liên 
quan mật thiết với đặc tính màu sắc của chúng. Các hợp chất màu (sắc tố) nói chung rất nhạy cảm với nhiệt độ cao, chúng biến đổi theo hướng bị mất màu hoặc sậm đi. Vì thế, đây là thông số chất lượng quan trọng phản ánh chất lượng cảm quan của sản phẩm sau khi sấy. Ảnh hưởng của nhiệt độ sấy đến hàm lượng 02 sắc tố carotenoids và chlorophyll được thể hiện qua Hình 3.
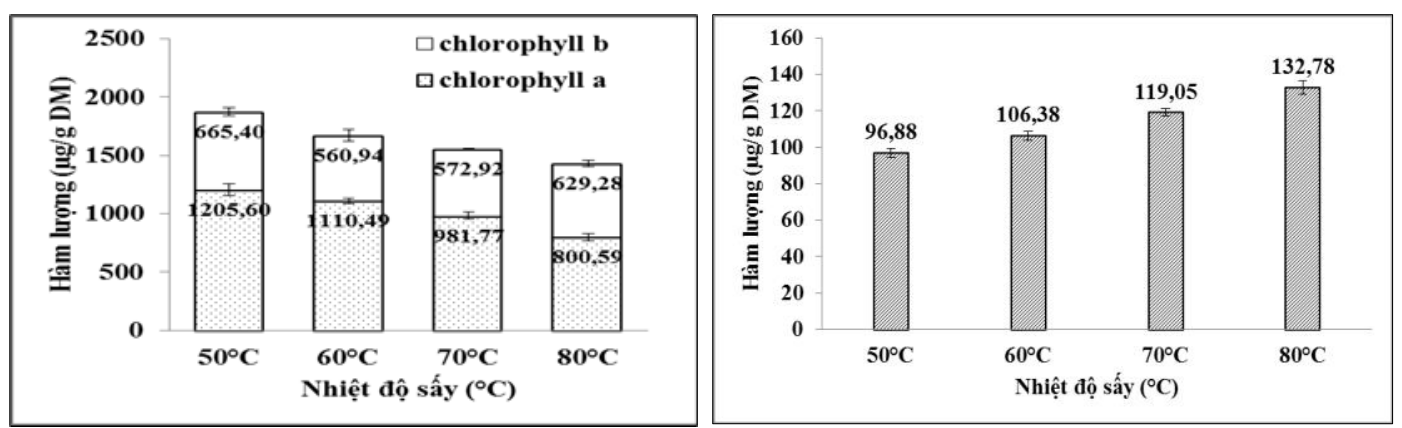

Hình 3. Hàm lượng sắc tố chlorophyll và carotenoids trong rau càng cua khi sấy ở các mức nhiệt độ khác nhau

Kết quả ở Hình 3 , cho thấy hàm lượng sắc tố chlorophyll có xu hướng giảm khi tăng nhiệt độ sấy. Trong đó, hàm lượng chlorophyll $\mathrm{a}$ và $\mathrm{b}$ được duy trì ở mức cao trong nguyên liệu khi sấy ở $50^{\circ} \mathrm{C}$ với hàm lượng chlorophyll tổng là $1,871.00(\mu \mathrm{g} / \mathrm{g} \mathrm{DM})$. Hàm lượng sắc tố chlorophyll a và b bị suy giảm nhiều nhất khi sấy ở $80^{\circ} \mathrm{C}$ với hàm lượng chlorophyll tổng chỉ còn $1,429.83(\mu \mathrm{g} / \mathrm{g} \mathrm{DM})$. Theo (Cui, $\mathrm{Xu}, \& \mathrm{Sun}, 2015)$ tính kháng nhiệt và nồng độ nhận biết của sắc tố chlorophyll $\mathrm{a}$ và chlorophyll $\mathrm{b}$ là khác nhau, trong đó sắc tố chlorophyll $\mathrm{b}$ có sự kháng nhiệt tốt hơn chlorophyll $\mathrm{b}$; về màu sắc chlorophyll a tạo màu xanh đậm, chlorophyll b tạo màu xanh vàng.

Về sự biến đổi hàm lượng của sắc tố carotenoids theo nhiệt độ sấy lại cho thấy sắc tố này có tính kháng nhiệt cao hơn sắc tố chlorophyll khi có khuynh hướng tăng hàm lượng khi tăng nhiệt độ sấy. Hàm lượng carotenoids trong cây rau càng cua được duy trì tốt nhất khi sấy ở $80^{\circ} \mathrm{C}$ và khác biệt có ý nghĩa thống kê ở mức ý nghĩa $5 \%$ so với các mẫu còn lại với hàm lượng là $132.78(\mu \mathrm{g} / \mathrm{g} \mathrm{DM})$. Kết quả nghiên cứu này tương tự với kết quả nghiên cứu sấy quả dâu tây vàng khi hàm lượng $\beta$-caroten được duy trì tốt ở $80-90^{\circ} \mathrm{C}$ và khác biệt không có ý nghĩa thống kê với hàm lượng $\beta$-caroten trong mẫu dâu nguyên liệu, mẫu dâu sấy ở $50^{\circ} \mathrm{C}$ và $70^{\circ} \mathrm{C}$ có hàm lượng $\beta$-caroten thấp nhất. Theo (Demiray, Tulek, \& Yilmaz, 2013) sự suy giảm sắc tố carotenoids được hạn chế khi sấy ở nhiệt độ cao là do tăng nhiệt độ sấy làm giảm thời gian sấy, điều này có tác dụng hạn chế quá trình tự oxy hóa của sắc tố carotenoids.

Qua các kết quả thí nghiệm trên cho thấy, nhiệt độ sấy rau càng cua thích hợp nhất để giữ lại hàm lượng hợp chất TPP và có hoạt tính chống oxy hóa cao đồng thời giữ lại màu sắc khá tốt là sấy ở $70^{\circ} \mathrm{C}$ cho đến khi rau càng cua đạt độ ẩm $\leq 10 \%$.

\section{Kết luận}

Nhiệt độ sấy rau càng cua thích hợp nhất là $70^{\circ} \mathrm{C}$. Chế độ sấy rau càng cua ở nhiệt độ $70^{\circ} \mathrm{C}$ vừa có tác dụng hạn chế thấp nhất sự hao hụt hàm lượng hợp chất $\mathrm{TPP}$, đồng thời tạo sản phẩm sấy có giá trị cảm quan tốt với màu sắc tươi sáng. Dịch trích mẫu rau càng cua sấy ở $70^{\circ} \mathrm{C}$ có hàm lượng hợp chất TPP là $12.88(\mathrm{mgGAE} / \mathrm{g} \mathrm{DM})$; sắc tố carotenoids là $119.05(\mu \mathrm{g} / \mathrm{g} \mathrm{DM})$, chlorophyll a và b lần lượt là 981.77 và $572.92(\mu \mathrm{g} / \mathrm{g} \mathrm{DM})$ và có khả năng chống oxy hóa tốt với phần trăm gốc tự do DPPH bị khử là $69.54 \%$. 


\section{LỜI CÁM ƠN}

Chân thành gửi lời cảm ơn đến Khoa Nông nghiệp \& Công nghệ Thực phẩm, Trường Đại học Tiền Giang đã tạo điều kiện để chúng tôi hoàn thành nghiên cứu này.

\section{Tài liệu tham khảo}

Aluko, B. T., Alli, S .Y. R., \& Omoyeni, O. A. (2014). Phytochemical analysis and antioxidant activities of ethanolic leaf extract of Brillantaisia patula. World Journal of Pharmaceutical Research, 3(3), 4914-4924.

Cui, Z. W., Xu, S. Y., \& Sun, D. W. (2015). Effect of microwave-vacuum drying on the carotenoids retention of carrot slices and chlorophyll retention of Chinese chive leaves. Drying Technology, 22(3), 563-575. doi:10.1081/DRT-120030001

Demiray, E., Tulek, Y., \& Yilmaz, Y. (2013). Degradation kinetics of lycopene, $\beta$-carotene and ascorbic acid in tomatoes during hot air drying. LWT Food Science and Technology, 50(1), 172-176.

Dwivedy, S., Rayaguru, K., \& Sahoo, G. R. (2012). Effect of drying methods on quality characteristics of medicinal Indian Borage (Coleus aromaticus) leaves. Food Processing and Technology, 3(11), 1-6.

Guan, X., \& Yao, H. (2008). Optimization of viscozyme L assisted extraction of oat bran protein using response surface methodology. Food Chemistry, 106(1), 345-351.

Huynh, M. T. B., \& Nguyen, P. K. (2018). Ảnh hưởng của nhiệt độ và thời gian sấy đến chất lượng của quả mãng cầu gai (Annona muricata L.) [Influence of temperature and drying time on quality of soursop (Annona muricata L.)]. Tạp chí Khoa học Đại học Trà Vinh, 30, 86-91.

Le, T. N. (2003). Hóa học thục phẩm [Food chemistry]. Hanoi, Vietnam: NXB Khoa học và kỹ thuật Hà Nội.

Lopez, J., Galvez, A.V., Torres, M. J., Mondaca, R. L., Quispe, I., \& Scala, K. D. (2013). Effect of dehydration temperature on physico-chemical properties and antioxidant capacity of golden berry (Physalis peruviana L.). Chilean Journal of Agricultural Research, 73(3), 293-300. doi:10.4067/S0718-58392013000300013

Nguyen, T. D. (2019). Nghiên cứu ảnh hưởng của quá trình thu hoạch và chế biến đến hàm lương các chất có hoạt tính sinh học trong cây thuốc dòi (Pouzolzia zeylanica L. Benn) [Effect of harvesting and processing on bioactive compounds content in medicinal plant, case study of Pouzolzia zeylanica L. Benn] (Doctoral dissertation, Can Tho University, Can Tho, Vietnam).

Nguyen, V. Q., Nguyen, H. T. M., Trinh, C. X., \& Nguyen, H. N. (2014). Ảnh hưởng của nhiệt độ sấy đến hàm lượng polyphenol tổng số và khả năng kháng oxi hóa của đài hoa bụp giấm (Hibiscus sabdariffa L.) [An effect of drying temperature on total polyphenolic content and antioxidant activity of roselle calyxes (Hibiscus Sabdariffa L.)]. Tạp chí Khoa hoc Đại học An Giang, 4(3), 74-78.

Schweiggert, U. R., \& Schieber, A. (2007). Conventional and alternative processes for spice production. A review, Trends Food Science Technology, 18, 260-268. 
Truong, T. Q., \& Nguyen, K. D. (2020). Đánh giá sụ ảnh hưởng của chế độ sấy đến hàm luợng hợp chất polyphenol tổng số, các hợp chất màu và hoạt tính chống oxy hóa của lá tía tô (Perilla frutescens L.) trồng ở huyện Châu Thành, tỉnh Tiền Giang [Assessment of the effects of drying mode to the content of total polyphenol, color compounds and the antioxidative activity of the perilla leafs (Perilla frutescens L.) in Chau Thanh district, Tien Giang province] (Báo cáo Khoa học Hội nghị Công nghệ Sinh học toàn quốc năm 2020). Đại học Huế, Thừa Thiên Huế, Vietnam. Retrieved April 10, 2021, from http://huib.hueuni.edu.vn/wp-content/uploads/2020/12/340-345.pdf

Uddin, S. N., Akond, M. A., Mubassara, S., \& Yesmin, M. N. (2008). Antioxidant and antibacterial activities of trema cannabina. Middle-East Journal of Scientific Research, 3(2), 105-108.

Yadav, R. N. S., \& Agarwala, M. (2011). Phytochemical analysis of some medicinal plants. Journal of Phytology, 3(12), 10-14.

Yousefi, S., Emam-Djomeh, Z., \& Mousavi, S. M. (2011). Effect of carrier type and drying on the physicochemical properties of powdered and reconstituted pomegranate juice (Punica Granatum L.). Journal of Food Science and Technology, 48(6), 677-684. doi:10.1007/s13197-010-0195-x 